\title{
Produção de Biodiesel a partir de óleo de soja empregando catalisadores heterogêneos contendo potássio
}

\author{
P. S. Batista, G. O. Rodrigues, B. G. Rodrigues e M. N. Sousa \\ Escola de Engenharia de Lorena, Departamento de Engenharia Química - EEL/USP \\ marivone@dequi.eel.usp.br
}

\begin{abstract}
RESUMO - Neste trabalho foram estudados o desempenho de catalisadores sólidos à base de potássio suportado em de óxido de zircônio ou óxido de nióbio, para a produção de biodiesel de óleo de soja, bem como a comparação de suas atividades usando o etanol e o metanol. Os catalisadores de $10,5 \%$ e $20,9 \%$ de $\mathrm{K}$ foram preparados por impregnação seca utilizando soluções alcoólicas de hidróxido de potássio na concentração desejada para a obtenção do teor final As reações foram realizadas na temperatura de refluxo do álcool, $10 \% \mathrm{~m} / \mathrm{m}$ catalisador em relação ao óleo com variadas razões molares de álcool/óleo e tempo de reação igual a 2,5 ou $5 \mathrm{~h}$. O produto final foi submetido a etapas de separação e purificação. Para a determinação da conversão em biodiesel foi empregada a espectroscopia de ressonância magnética nuclear de hidrogênio ( $\left.\mathrm{RMN}^{\top} \mathrm{H}\right)$. Os resultados obtidos mostraram conversões maiores do que $96 \%$ para os catalisadores suportados em óxido de zircônio, independentemente do teor de $\mathrm{K}$, enquanto aqueles suportados em óxido de nióbio foram menos ativos. Uma amostra foi caracterizada quanto a viscosidade e massa específica, nas condições padronizadas pelas normas exigidas pela Agência Nacional do Petróleo e Biocombustíveis (ANP), mostrando estar dentro dos padrões, podendo ser considerada biodiesel.
\end{abstract}

Palavras- chave: biodiesel, catalisadores heterogêneos, potássio

\section{INTRODUÇÃO}

Atualmente, devido aos danos ambientais causados pelo uso de combustíveis fósseis, há um grande aumento na busca por diferentes fontes de energia renovável. Dentre essas, os biocombustíveis vêm conquistando grande importância mundial, por ser uma opção biodegradável e não-tóxica. O biodiesel, combustível derivado de óleo vegetal ou gordura animal, apresenta baixa emissão de poluentes como monóxido de carbono e hidrocarbonetos (Ferrari et al., 2005).

No Brasil, devido a regra estabelecida pelo Conselho Nacional de Política Energética (CNPE), todo óleo diesel comercializado contém 5\% de biodiesel, tornando o país destaque mundial na produção e consumo de biodiesel, associado a ampla variedade de matérias- primas de espécies vegetais, como soja, dendê, girassol, babaçu, amendoim, mamona e pinhão- manso. 
Para se tornar compatível como os motores a diesel, o óleo, de origem animal ou vegetal, deve passar por um processo químico de diminuição de sua viscosidade e, dentre eles, a reação de transesterificação é o mais usado, onde o óleo, juntamente com um álcool de cadeia curta, reagem na presença de um catalisador, formando o biodiesel e outros subprodutos.

A escolha do tipo de catalisador a ser usado é de grande importância, pois define a viabilidade econômica do processo. Maiores conversões são observadas quando catalisadores homogêneos são usados, principalmente quando o óleo contém ácidos graxos livres. Porém o processo homogêneo apresenta desvantagens, como a formação de sabão como subproduto e a difícil separação do catalisador no fim da reação, ao contrário do processo heterogêneo, em que o catalisador pode ser facilmente separado e reutilizado, diminuindo os custos de produção.

O álcool a ser utilizado na transesterificação também tem grande influência no processo. O metanol, por ser um álcool de menor custo na maioria dos países, é comumente mais empregado. Porém, em países onde o etanol é mais barato, como é o exemplo do Brasil, é vantajoso utilizá-lo, levando assim a uma maior economia, além de se tratar de um álcool nãotóxico, ao contrário do metanol.

A reação de transesterificação é demonstrada na Figura 1.
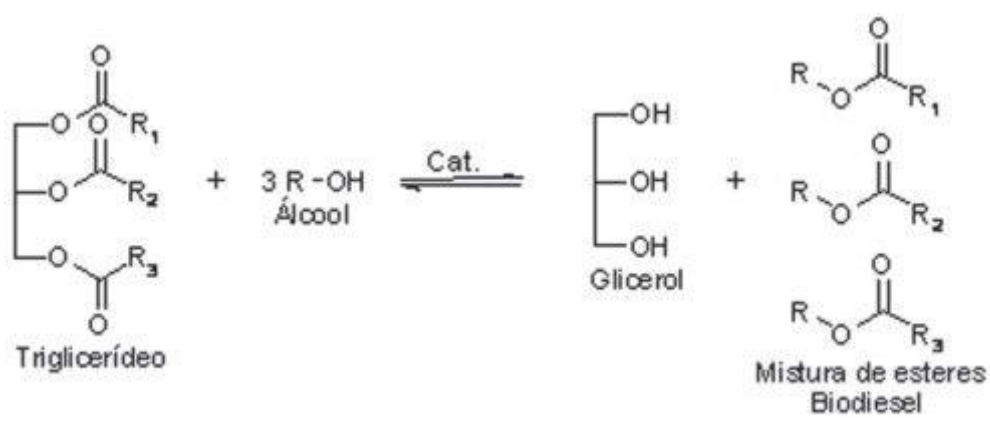

Figura 1. Reação de transesterificação

\subsection{Catalisadores heterogêneos}

Pesquisas vêm sendo realizadas na área de desenvolvimento de catalisadores heterogêneos para a transesterificação de óleos e gorduras, buscando vantagens como simplificação do processo de purificação do biodiesel e fácil reutilização do catalisador. Os catalisadores heterogêneos que apresentam potencial para a produção do biodiesel, seja por processos de esterificação ou de transesterificação, sendo divididos nas seguintes classes: óxidos e sais inorgânicos, zeólitas, compostos de coordenação e líquidos iônicos, resinas trocadoras de íons, ácidos e bases orgânicos e materiais lamelares. 


\section{EXPERIMENTAL}

\section{Preparação dos catalisadores}

Duas séries de catalisadores de potássio suportado foram preparadas, uma empregando o óxido de nióbio (nióbia) e outra o óxido de zircônio (zircônia). A escolha dos teores de potássio foi baseada inicialmente no trabalho de Carvalho (2011). Como precursor do potássio foi escolhido o composto na forma de hidróxido devido ao baixo custo econômico. Após a determinação do volume poroso aparente dos dois suportes e devido ao limite de solubilidade do $\mathrm{KOH}$ em etanol, foi preparada uma solução etanólica de hidróxido de potássio para a impregnação de cada suporte. Para a obtenção do teor desejado foi necessário duplicar ou triplicar a etapa de impregnação. $\mathrm{O}$ sólido após a impregnação foi submetido à secagem a $110^{\circ} \mathrm{C}$ por 90 minutos. Após a secagem final, o precursor do catalisador foi levado à calcinação em mufla a $200^{\circ} \mathrm{C}$ por 24 horas. A simbologia para apresentação dos resultados obtidos com os catalisadores será o teor de potássio, a letra $\mathrm{K}$, e as letras $\mathrm{N}$ e Z para a nióbia e a zircônia, respectivamente.

\section{$\underline{\text { Reações de transesterificação }}$}

As reações foram realizadas em reatores esféricos na temperatura de refluxo do álcool, etanol a $78,5^{\circ} \mathrm{C}$ ou metanol a $64,7^{\circ} \mathrm{C}$, com agitação mecânica ou magnética, com tempos de reação iguais a 2,5 e 5,0h. O óleo de soja utilizado foi o da marca Liza, o etanol da Synth $(99,5 \%)$ e o metanol da Merck. As reações foram realizadas em três etapas, inicialmente com um sistema com agitação mecânica que depois foi substituído pelo de agitação magnética e a terceira etapa com o metanol. A quantidade de catalisador foi mantida constante em $10 \%$ em massa em relação à quantidade de óleo. A razão molar álcool/óleo foi variada de 6 a 72. A reação de transesterificação do óleo de soja (triglicerídeo) com álcool resulta no éster (biodiesel) e no glicerol, sendo assim, ao final da reação, o produto foi filtrado à vácuo para a retirada do catalisador, em seguida foi lavado com água a $70^{\circ} \mathrm{C}$, por três vezes. Após a última lavagem a fração contendo o biodiesel foi levada a centrifugação para remoção de traços de água ou sabão. Para finalizar a purificação do biodiesel, este foi submetido à evaporação rotativa à $78^{\circ} \mathrm{C}$ por 20 min, para a retirada de traços de álcool. Para certificação da remoção dos traços de água o biodiesel centrifugado foi colocado em contato com um leito de sulfato de sódio anidro por uma noite. Em seguida, foi centrifugado para separação do sal e guardado em frasco âmbar em geladeira.

\section{Caracterização dos catalisadores}

Os catalisadores $10 \mathrm{KN}, 10 \mathrm{KZ}, 20 \mathrm{KN}$ e $20 \mathrm{KZ}$ foram caracterizados por Espectrometria de Absorção Atômica (EAA) para a quantificação de seus teores de potássio, através do método de determinação direta. Também foram submetidos à análise por Difração de Raios- X (DRX), empregando- se a técnica do pó, em um aparelho da marca SEIFERT modelo ISSODEBYEFLEX 1001, com radiação $\mathrm{Cu} \mathrm{K} \alpha$ com filtro de Ni. A tensão e a corrente utilizadas nos experimentos foram de $40 \mathrm{KV}$ e $30 \mathrm{~mA}$, respectivamente. Os ângulos de Bragg (20) foram varridos entre 10 e 80 graus, com passo angular de 0,05 e tempo de contagem de 3 s por ponto.

\section{Caracterização do biodiesel}


Para a caracterização do biodiesel, as amostras foram dissolvidas em clorofórmio deuterado para análise por Ressonância Magnética Nuclear de Hidrogênio (RMN- $\mathrm{H}^{1}$ ) num espectrômetro marca Varian - modelo Mercury-300 MHz. O cálculo da conversão foi feito com auxílio do software Mestre C, utilizando a metodologia proposta por Garcia (2006), que consiste na identificação das moléculas presentes na região de 4,05-4,35 ppm para os ésteres etílicos. $\mathrm{O}$ mesmo método foi empregado por Carvalho (2011) que mostra que o pico de ressonância dos átomos de hidrogênio metilênicos dos ésteres etílicos é desdobrado em um quarteto, cuja área total é a somatória dos componentes externos do quarteto, que possuem uma área igual a 1/8 da área total, mais os componentes internos, que tem áreas iguais a 3/8 da área total do quarteto, conforme a figura 2 , sendo que o primeiro pico é único que não apresenta sobreposição de nenhum outro subproduto formado em etapas intermediárias e por este motivo é utilizado como ponto de partida para o cálculo de conversão, este pico deve ser encontrado por volta de 4,08 ppm.

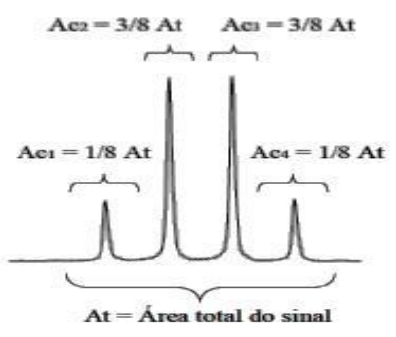

Figura 2. Espectro de RMN-H ${ }^{1}$

Deste modo é possível calcular a conversão em ésteres etílicos, a partir dos cálculos de área dos picos, conforme a fórmula:

$$
\text { \%Conversão }=[\{(\mathrm{Ac} 4) \times 8\} /(\mathrm{At})] \times 100
$$

onde: Ac4 é área do primeiro pico, em 4,08 ppm, que não sofre sobreposição; e At é a soma da área dos quatro picos, presentes entre 4,05-4,35 ppm.

As normas em vigor da Agência Nacional do Petróleo, Gás Natural e Biocombustíveis ANP, Resolução $\mathrm{n}^{\circ} 14$ de 11 de maio de 2012, regulam as exigências para o produto ser qualificado como biodiesel:

- viscosidade cinemática a $40^{\circ} \mathrm{C}$ estar entre $3-6 \mathrm{~mm}^{2} / \mathrm{s}$,

- a massa específica a $20^{\circ} \mathrm{C}$ entre $850-900 \mathrm{~kg} / \mathrm{m}^{3} \mathrm{e}$

- Conversão > 96,5\%

Sendo assim, foi usado um viscosímetro para a medição da viscosidade de uma amostra escolhida, utilizando-se o aparelho de modelo LVDVIIICP-CP 520 da Brookfield e densímetro modelo DMA 35N da Anton Paar para a determinação da viscosidade cinemática e densidade. 


\section{RESULTADOS E DISCUSSÃO}

Os resultados do teor de potássio contido nos catalisadores, obtidos por espectrometria de absorção atômica (EAA), estão apresentados na Tabela 1. A análise dos valores obtidos comparados aos valores teóricos mostraram um desvio médio de $\pm 2,4 \%$, exceto teor mais alto de $\mathrm{K}$ suportado em zircônia que devido a baixa adsorção deste óxido e por ter sido usada a impregnação em três etapas teve erro de $19,5 \%$. Os demais catalisadores estão de acordo com o erro experimental devido método de impregnação empregado.

\begin{tabular}{llr}
\multicolumn{2}{l}{ Tabela $1-$ Teor de K nos catalisadores $(\% \mathrm{~m})}$. \\
\hline Catalisador & $\begin{array}{l}\text { Teor de K } \\
\text { teórico }\end{array}$ & $\begin{array}{l}\text { Teor K por } \\
\text { EAA }\end{array}$ \\
\hline $\mathbf{1 0 K Z}$ & 10,45 & 10,58 \\
$\mathbf{1 0 K N}$ & 10,45 & 9,91 \\
$\mathbf{2 0 K Z}$ & 20,91 & 16,83 \\
$\mathbf{2 0 K N}$ & 20,91 & 21,56 \\
\hline
\end{tabular}

A partir dos resultados das análises por difração de raios-X, obtidos com a utilização do software específico e por comparação com as fichas cristalográficas das fases cristalinas de ambos os óxidos, foi possível observar que o suporte óxido de nióbio é amorfo enquanto o óxido de zircônio é cristalino e apresenta fase monoclínica.

Os resultados de conversão em ésteres (ou biodiesel) obtidos nas reações de transesterificação, estão apresentados nas Figuras 3 a 5. Inicialmente, os catalisadores à base de potássio foram testados empregando o etanol na reação de transesterificação, com razão molar igual a 72, nas mesmas condições empregadas por Carvalho (2011) a fim de comparar a eficiência com sistemas à base de sódio suportado em nióbia, com agitação mecânica. Os resultados obtidos não mostraram alteração na atividade dos sistemas catalíticos devido ao tipo de agitação, mecânica ou magnética, pois não afetou o rendimento da reação. Nestes experimentos, mostrados na Figura 3, empregando razão molar etanol/óleo igual a 72, pode ser observado que em apenas 2,5h a conversão alcança o rendimento máximo mesmo quando o teor de potássio é de $10 \%$ se suportado em zircônia. Os resultados mostram que o aumento do teor de $\mathrm{K}$ nos catalisadores foi um fator muito relevante, principalmente quando o suporte é a nióbia, pois o sistema contendo $10 \% \mathrm{~K}$ não apresentou atividade, mesmo quando a reação foi conduzida por $40 \mathrm{~h}$. No entanto, o catalisador contendo $20 \%$ de $\mathrm{K}$ suportado em nióbia $(20 \mathrm{KN})$ apresentou conversões maiores do que $96 \%$. Os catalisadores com melhor desempenho foram aqueles onde o suporte empregado foi a zircônia, que mesmo com teor de $10 \%$ de K apresentou conversão de $97 \%$. Foram realizados testes em branco, ou seja, nas mesmas condições de reação, empregando apenas os óxidos puros e não foi observada atividade dos mesmos. Na segunda fase dos testes, os catalisadores foram testados na reação de transesterificação do óleo de soja com metanol e os resultados estão apresentados nas Figuras 4 e 5. 


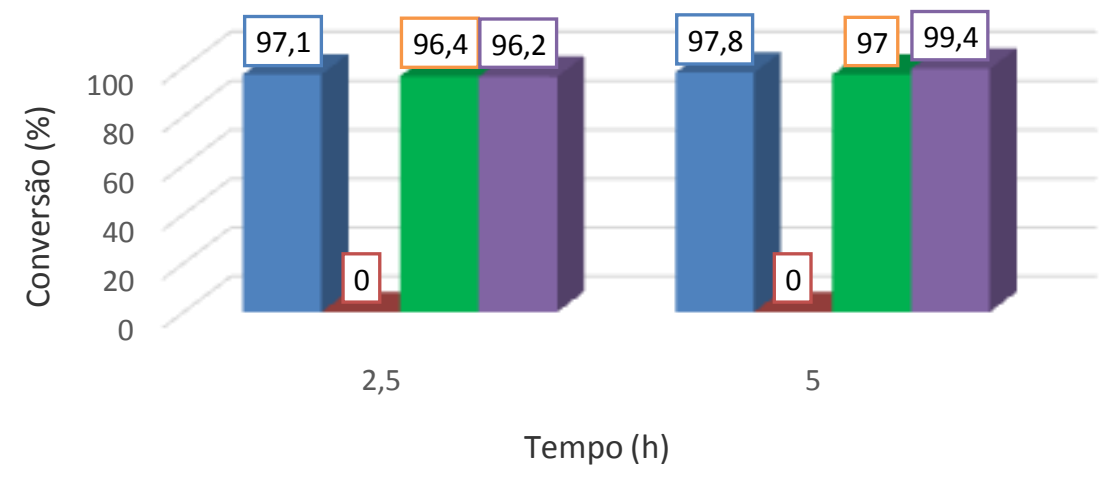

$\square 10 \mathrm{KZ} \square 10 \mathrm{KN} \square 20 \mathrm{KZ} \square 20 \mathrm{KN}$

Figura 3 - Rendimentos em biodiesel de soja com etanol (RM=72)

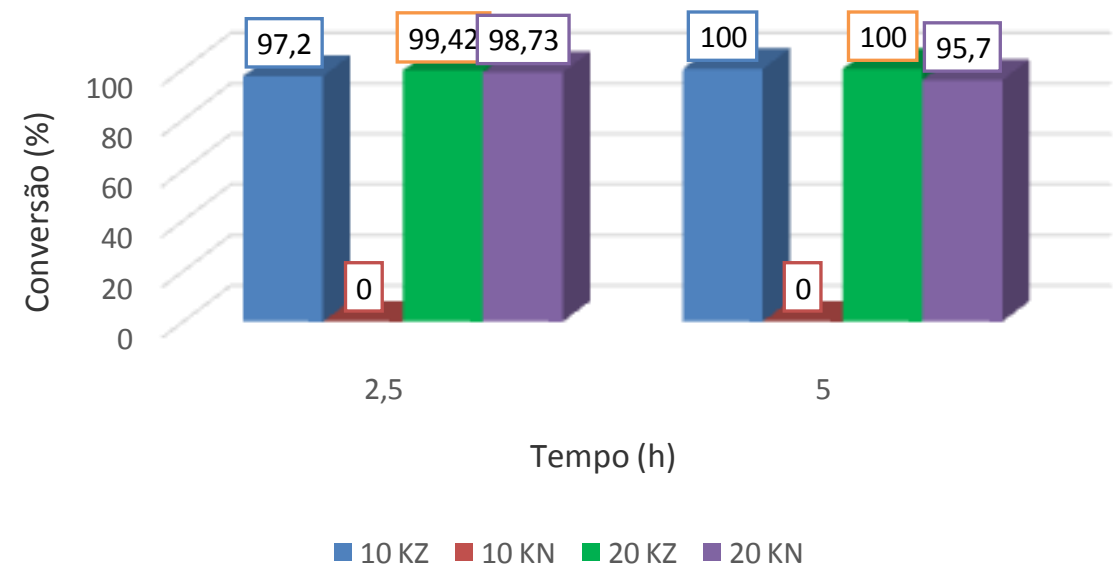

Figura 4 - Rendimentos em biodiesel de soja com metanol $(\mathrm{RM}=6)$ 


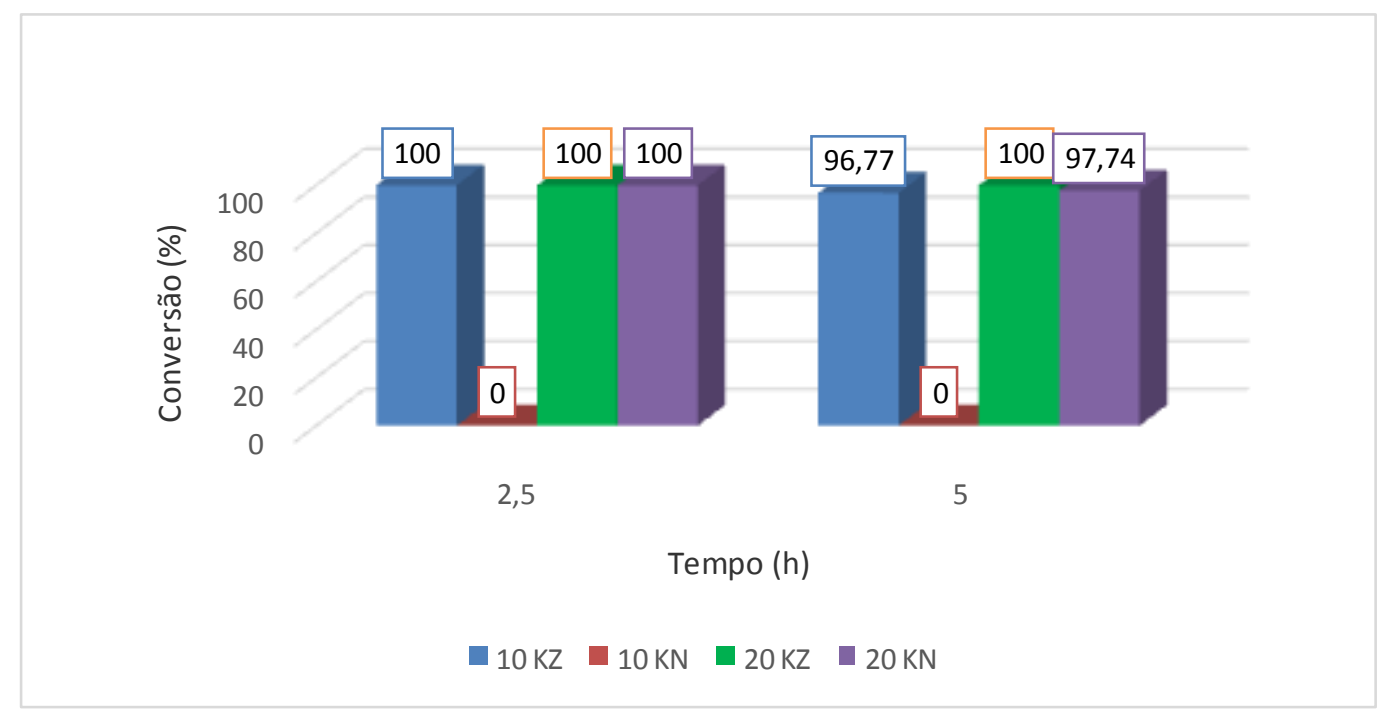

Figura 5 - Rendimentos em biodiesel de soja com metanol (RM=15)

A reatividade do metanol é maior do que a do etanol conforme publicado em diversos trabalhos na literatura, sendo assim as razões molares de álcool:óleo empregadas foram iguais a 6 e 15. No entanto, o emprego do metanol não melhorou a atividade do catalisador $10 \mathrm{KN}$ que não mostrou atividade nas condições empregadas. Os rendimentos alcançaram conversão total em vários experimentos, mostrando a otimização da reação de transesterificação com menor quantidade de álcool e rendimentos que asseguram o exigido pela ANP para a produção de biodiesel.

Uma amostra de biodiesel etílico, com rendimento de conversão em biodiesel maior do que $96,5 \%$, foi escolhida a obtida com $99,3 \%$ a qual foi submetida a testes de viscosidade e de densidade. A amostra apresentou viscosidade igual a $4,8 \mathrm{~mm}^{2} / \mathrm{s}$ e massa específica igual a 877,2 $\mathrm{kg} / \mathrm{m}^{3}$, nas temperaturas padronizadas pela norma, mostrando estar dentro dos padrões exigidos pela ANP para ser considerada biodiesel.

\section{CONCLUSÕES}

O rendimento da reação de transesterificação do óleo de soja, nas condições empregadas, não foi alterado quando utilizada a agitação mecânica em substituição à magnética, portanto os testes na segunda fase foram realizados com agitação magnética por ser a mais adequada para pequenas quantidades de reagentes. O emprego do cálculo das conversões em biodiesel por Ressonância Magnética Nuclear de Hidrogênio (RMN-H) mostrou ser de grande auxílio quando a análise por cromatografia não está disponível. A partir dos resultados obtidos concluímos que o potássio suportado aos óxidos de nióbio e zircônio promoveu catalisadores ativos para a produção de biodiesel. 


\section{NOMENCLATURA}

Os catalisadores seguiram a seguinte nomenclatura:

$10 \mathrm{KZ}$ - catalisador contendo $10 \% \mathrm{~K}$ suportado em zircônia;

$10 \mathrm{KN}$ - catalisador contendo $10 \%$ K suportado em nióbia

20KZ - catalisador contendo 20\% K suportado em zircônia;

$20 \mathrm{KN}$ - catalisador contendo $20 \%$ K suportado em nióbia;

\section{REFERÊNCIAS}

CARVALHO, A. K. F., Síntese de biodiesel por transesterificação pela rota etílica: Comparação do desempenho de catalisadores homogêneos. Dissertação (Mestrado) - Escola de Engenharia de Lorena, Universidade de São Paulo, Lorena - SP, 2011

FERRARI, R. A.; OLIVEIRA, V. S.; SCABIO, A. Biodiesel de soja: taxa de conversão em ésteres etílicos, caracterização físico-química e consumo em gerador de energia. Química Nova, v.28, p. 19-23, 2005

GARCIA, C. M. Transesterificação de óleos vegetais. Dissertação (Mestrado) -Universidade Estadual de Campinas, Campinas - SP, 2006 